\section{HELP PREVENT BIOFILM BUILD-UP}

Aspirmatic cleaner from schülke - experts in infection prevention and control - is designed for cleaning dental suction systems and spittoons. Regular use helps prevent the build-up of biofilm.

During routine use of the suction unit, organic and inorganic substances can be deposited which may dry in the tubes potentially leading to contamination and the risk of cross infection for staff when changing the filter. Aspirmatic is effective against bacteria (including salmonella and legionnella), fungi and viruses (including HCV, HBV, HIV) in 30 minutes.
Extensive testing of Aspirmatic in dental practices has shown the non-foaming formulation is quick and easy to use, with a broad spectrum of efficacy. Aspirmatic has a three in one action and cleans, disinfects and deodorises in a single application.

A two litre bottle reconstitutes to 100 litres, helping to save on storage space as well as cost.

To find out more visit www.schuelke.com or contact: schülke UK, Cygnet House, 1 Jenkin Road, Meadowhall, Sheffield, S9 1AT / 01142543500 / email: mail.uk@schuelke.com

\title{
THE POWER OF A HEALTHY SMILE
}

UK parents are keen to invest in improving the smiles of their children. That's according to a new survey ${ }^{1}$ of over 2,000 adults.

Responses reveal that fixing their children's teeth would be high on the priority list if they won $£ 5,000$ to spend on future-proofing their children.

The survey - conducted on behalf of Align Technology, the global company behind Invisalign clear aligners - sought parents' attitudes towards investment in their children's future, as well as their own. A quarter (24\%) of parents cited teeth straightening as an investment of choice.

When asked what troubled their children the most about their appearance, $21 \%$ of parents revealed their child often felt their teeth and smile concerned them, compared with $19 \%$ sensitive about the condition of their skin and $17 \%$ worried about weight.

Respondents said they would happily help their children improve their smile in a bid to boost confidence (40\%) - with teeth straightening deemed the most acceptable procedure to embrace in order to change their facial appearance (39\%).

Parents were also keen to address their child's crooked teeth if it meant putting paid to potential bullying (23\%) or raising

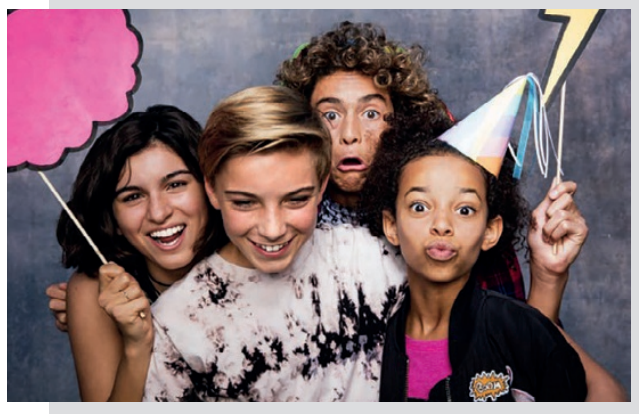

the bar for long-term life success, with $15 \%$ happy to pay for teeth-straightening treatment to boost their kids' school achievements (15\%).

Align Technology has tailored its Invisalign product to meet the needs of teenagers as the system includes a number of features to help orthodontists treat younger patients - including its latest mandibular advancement options.

The aligner series work incrementally changed every one to two weeks - as teeth are gently repositioned into alignment. Because they are removable, the aligners have little impact on speech, eating and drinking and socialising. Plus, if wearers have a major event coming up, they are easily removable for short periods of time - although the optimum wear time is 22 hours a day.

According to the survey, if given $£ 5,000$ to spend on themselves, parents were more likely to fix and whiten their own teeth. These treatments were more popular than Botox, lip fillers, a facelift, nose job, a tattoo or a nose piercing - with the majority citing their smile as the part of their appearance about which they were most self-conscious. Align Technology designs and manufactures the Invisalign system and iTero intraoral scanners. For more information, please visit: www.invisalign.co.uk.

1. Investing in the Future - conducted for Invisalign The survey of 2002 UK adults, $50 \%$ male and $50 \%$ female took place between 20th-23rd April 2018. Participants came from 12 regions in the UK and were from a variety of socio economic UK and were from a variety of socio economic
backgrounds. A (10\%), B (27\%), C1 (17\%), C2 (15\%), $\mathrm{D}(9 \%), \mathrm{E}(22 \%) .81 \%$ of participants had 1 or more children, $83 \%$ of those children were aged 10 or more. Participants were asked a range of questions based on their attitudes to investing in the future or themselves and their children.

\section{DENTAL ELITE CAN HELP}

As concerns mount over recruitment issues and impaired growth of dental businesses, assistance from a specialist agency with dental experience is more vital than ever.

Dental Elite has many years collective experience across the team, and with a customer rating of 4.8 out of 5 , it is one of the profession's must trusted agencies, covering recruitment, sales and acquisitions, valuations and finance.

'I would definitely recommend Dental Elite to others, and would certainly give them a call if I ever needed to find another job in the future, says associate Justin George.

\section{STEAMLINING CLINICAL SOLUTIONS}

Manufacturer W\&H has got several new solutions in its range to help streamline clinical procedures. Among them are the Lisa type $B$ vacuum sterilizer, featuring Eco Dry technology that adapts the drying time to the mass of each load. For dental practices which provide implants, they have the Osstell Beacon handheld device, which identifies when an implant is ready for loading, thereby improving osseointegration.

Assistina TWIN handpiece care and maintenance unit provides a costeffective solution to extending the working life of handpieces

These innovative products make up an exciting catalogue of high quality dental technology, that also includes the Piezomed unit and the awardwinning Synea Vision range of powerful handpieces.

To find out more visit www.wh.com/ en_uk, call 01727874990 or email office. uk@wh.com 